\title{
Sanitizantes clorados no setor alimentício: mini-revisão
}

\section{Chlorine sanitizers in the food sector: mini review}

DOI: $10.46814 /$ lajdv3n4-067

Recebimento dos originais: 01/05/2021

Aceitação para publicação: 31/06/2021

\section{Eder Júlio de Jesus}

Doutorando do Programa de Pós-Graduação em Ciência e Tecnologia de Alimentos - UFG/EA;

E-mail: ederjulio@discente.ufg.br

\section{Elaine Alves dos Santos}

Doutora em Ciência e Tecnologia de Alimentos

Instituto Federal de Educação, Ciência e Tecnologia do Triângulo Mineiro - Campus Uberlândia

(IFTM)

E-mail: elaine.alves@iftm.edu.br

\section{Ana Carolina de Jesus Oliveira}

Doutoranda do Programa de Pós-Graduação em Ciência e Tecnologia de Alimentos - UFG/EA; Email: carolina_jesus@discente.ufg.br

\section{Luis Carlos Cunha Júnior}

Engenheiro Agrônomo, PhD, Professor de Pós-colheita Vegetal da Escola de Agronomia Universidade Federal de Goiás - UFG, Goiânia, GO

E-mail: cunhajunior.1.c@ufg.br

\section{RESUMO}

A utilidade prática, aspectos positivos e desvantagens são mostrados nesta mini-revisão por meio da apresentação de uma fórmula prática para se calcular as dosagens de sanitizantes clorados (SC), a qual fornece a quantidade de cloro a ser utilizada na solução em grama $(\mathrm{g})$ ou mililitros $(\mathrm{ml})$ e duas figuras i) as concentrações cloradas já calculadas para locais que manipulam ou que processam alimentos e ii) com as vantagens e desvantagens dos SC. Os SC são muito utilizados no setor da agroindústria no mundo todo, no entanto, produzem cloramina, substância tóxica, cancerígena aos seres humanos. Alternativas ao uso do cloro se fazem necessárias como o ozônio $\left(\mathrm{O}_{3}\right)$, peróxido de hidrogênio $\left(\mathrm{H}_{2} \mathrm{O}_{2}\right)$, ácido peracético $\left(\mathrm{CH}_{3} \mathrm{CO}_{3} \mathrm{H}\right)$, raios ultravioletas com comprimento de onda de 250 a $275 \mathrm{~nm}$ por apresentarem atividade germicida. Estudos são necessários para diminuir o custo de aplicação destas tecnologias nas empresas.

Palavras-chaves: hipoclorito, cloramina, fórmula, sanitização, cloro.

\section{ABSTRACT}

The practical utility, positive aspects and disadvantages are shown in this mini-review by means a practical formula to calculate the dosage of chlorine sanitizers (CS), which provides the amount of chlorine being used in the solution in gram $(\mathrm{g})$ or milliliters $(\mathrm{ml})$ and two figuras i) concentrations as calculated for chlorinated sites that handle or process food and ii) the advantages and disadvantages of the CS. The CS are widely used in the agribusiness sector widely used in the agribusiness sector worldwide, however, produce chloramine, toxic, carcinogenic to humans. Alternatives to the use of chlorine are needed such as ozone $\left(\mathrm{O}_{3}\right)$, hydrogen peroxide $\left(\mathrm{H}_{2} \mathrm{O}_{2}\right)$, peroxyacetic acid or peracetic 
$\left(\mathrm{CH}_{3} \mathrm{CO}_{3} \mathrm{H}\right)$, ultraviolet rays with a wavelength of 250 to $275 \mathrm{~nm}$ by presenting germicidal activity. Studies are needed to reduce the cost of implementing these technologies in business.

Keywords: hypochlorite, chloramine, formula, sanitization, chlorine.

\section{INTRODUÇÃO}

Os sanitizantes clorados, em especial os hipocloritos, lideram a gama de aplicações no setor alimentício, seja pelo custo, pelo vasto espectro de ação e facilidade de aquisição. Tais sanitizantes são utilizados nas concentrações de 0,5 a $250 \mathrm{mg} . \mathrm{L}^{-1} \mathrm{em}$ tal setor. Isoni-Auad et al (2018), afirmam que os hipocloritos são eficazes contra as bactérias em geral, e moderadamente eficazes contra vírus, mofos, leveduras e esporos. Os sanitizantes clorados encontram-se disponíveis na forma de cloro orgânicos e inorgânicos.

Os primeiros compreendem conforme descrição de Germanos \& Germanos (2019), os hipocloritos de sódio, de cálcio, de lítio, o cloro gasoso e o dióxido de cloro; enquanto os segundos são a cloramina $\mathrm{T}$, dicloramina $\mathrm{T}$; dicloro dimetil hidantoína, ácido tricloroisocianúrico e ácido dicloroisocianúrico. Emmanuel. et al (2014), demonstram que formas de cloro orgânico combinados são mais estáveis, porém apresentam ação desinfetante mais lenta, requerendo longo tempo para sua exposição. Santos, Queiroz \& Almeida Neto, (2018), relatam que a água sanitária, para funcionar como bactericida eficaz, deve apresentar cerca de $2 \%$ de cloro residual.

Os mecanismos de ação dos compostos clorados sobre os microrganismos são os seguintes, conforme Germano \& Germano (2019) e Xi \& Yen-Com (2017), destruição da síntese protéica; descarboxilação oxidativa de aminoácidos a nitrilas e aldeídos; reação com ácidos nucléicos, purinas e pirimidinas; desequilíbrio metabólico após destruição de enzimas essenciais; indução de lesões no DNA acompanhada da capacidade de auto-duplicação; inibição da absorção de oxigênio e fosforilação oxidativa conjugada à quebra de macromoléculas e formação de derivados nitroclorados.

O presente trabalho teve por objetivo fazer uma revisão bibliográfica sobre os sanitizantes clorados no setor alimentício, enfocando a sua utilidade prática, aspectos positivos e desvantagens, sua utilidade prática bem como os aspectos positivos e desvantagens relacionados a aplicação deste método de sanitização.

\section{DESENVOLVIMENTO}




\subsection{FÓRMULA PARA CÁLCULO DA DOSAGEM DE SANITIZANTES CLORADOS (\#)}

Tal fórmula é bastante prática, pois pode ser utilizada para produtos clorados líquidos (ml) ou sólidos (g). Para o cloro gasoso, vide recomendações do fabricante. Em casos específicos para produtos clorados líquidos ou sólidos, também se deve ver as recomendações do fabricante.

\section{$\mathbf{q}=\underline{\mathbf{V} . \mathbf{p p m}}$}

\section{[ ]Cl.10}

Sendo:

$\mathbf{q}=$ quantidade de cloro em $\mathrm{g}$ ou $\mathrm{ml}$;

$\mathbf{V}=$ volume de água em litros;

ppm= parte por milhão (vide quadro 1$) \bullet ;$

[ ]Cl= concentração de cloro (vide rótulo dos produtos clorados e quadro 1)*;

$\mathbf{1 0}=$ constante.

\section{RESULTADOS}

Quadro 1 - Sugestões de soluções cloradas, já calculadas.

\begin{tabular}{|c|c|c|c|}
\hline \multicolumn{4}{|c|}{$\begin{array}{l}\text { Sugestões de uso de concentrações cloradas para sanitização em locais que manipulam ou que } \\
\text { processam alimentos }\end{array}$} \\
\hline & Solução• & $\begin{array}{c}\text { Cloro* } \\
2,5 \%\end{array}$ & $\begin{array}{c}\text { Cloro* } \\
12 \% \\
\end{array}$ \\
\hline $\begin{array}{l}\text { Enxágue das instalações, } \\
\text { vasilhames e equipamentos }\end{array}$ & 100 a 150ppm & $\begin{array}{c}40 \mathrm{Cl} \\
+ \\
10 \mathrm{~L} \text { de água } \\
\end{array}$ & $\begin{array}{c}8,5 \mathrm{Cl} \\
+ \\
10 \mathrm{~L} \mathrm{de} \mathrm{água} \\
\end{array}$ \\
\hline \multirow{2}{*}{$\begin{array}{l}\text { Água de chiller } \\
\text { (uso em alimentos) }\end{array}$} & $\begin{array}{l}\text { 02ppm } \\
\text { (mesa) }\end{array}$ & $\begin{array}{c}08 \mathrm{Cl} \\
+ \\
100 \mathrm{~L} \text { de água }\end{array}$ & $\begin{array}{c}02 \mathrm{Cl} \\
+ \\
\text { 100L de água }\end{array}$ \\
\hline & $\begin{array}{c}05 \mathrm{ppm} \\
\text { (processamento) }\end{array}$ & $\begin{array}{c}20 \mathrm{Cl} \\
+ \\
100 \mathrm{~L} \text { de água } \\
\end{array}$ & $\begin{array}{c}04 \mathrm{Cl} \\
+ \\
\text { 100L de água } \\
\end{array}$ \\
\hline $\begin{array}{l}\text { Utensílios guardados de um } \\
\text { dia para o outro submerso em } \\
\text { solução }\end{array}$ & $10 \mathrm{ppm}$ & $\begin{array}{c}04 \mathrm{Cl} \\
+ \\
10 \mathrm{~L} \mathrm{de} \mathrm{água} \\
\end{array}$ & $\begin{array}{c}1,0 \mathrm{Cl} \\
+ \\
10 \mathrm{~L} \text { de água }\end{array}$ \\
\hline Pedilúvio & $200 \mathrm{ppm}$ & $\begin{array}{c}40 \mathrm{Cl} \\
+ \\
\text { 05L de água }\end{array}$ & $\begin{array}{c}8,5 \mathrm{Cl} \\
+ \\
\text { 05L de água }\end{array}$ \\
\hline
\end{tabular}

Fonte: Elaborado pelos autores.

(\#) Em caso de dúvida, consultar um profissional habilitado da área de alimentos.

Lembrando que os tempos mínimos de exposição aos agentes clorados variam de fabricante para fabricante, mas geralmente são de cinco a quinze minutos. 
Quadro 2. Vantagens e desvantagens dos sanitizantes clorados.

\begin{tabular}{|l|l|}
\hline \multicolumn{2}{|l|}{ Vantagens de desvantagens dos hipocloritos como sanitizantes } \\
\hline Vantagens & Desvantagens \\
\hline Relativamente baratos & Instáveis ao armazenamento \\
\hline Agem rapidamente & Inativados pela matéria orgânica \\
\hline Não afetados pela dureza da água (Germano \& Germano, 2019) & $\begin{array}{l}\text { Corrosivos quando não usados corretamente (Germano \& } \\
\text { Germano, 2019) }\end{array}$ \\
\hline Efetivo contra uma variedade de microrganismos & Irritantes à pele (Germano \& Germano, 2019) \\
\hline Efetivos em baixas concentrações (Germano \& Germano, 2019) & Podem provocar odores indesejáveis (Germano \& Germano, 2019) \\
\hline $\begin{array}{l}\text { Relativamente não tóxicos nas condições de uso (Germano \& } \\
\text { Germano, 2019) }\end{array}$ & Precipitam em água contendo ferro \\
\hline Fácil preparo e aplicação & $\begin{array}{l}\text { Menor eficiência com aumento de pH da solução (Germano \& } \\
\text { Germano, 2019) }\end{array}$ \\
\hline Concentrações facilmente determinadas & Removem carbono da borracha (Germano \& Germano, 2019) \\
\hline Podem ser usados no tratamento de água & $\begin{array}{l}\text { Formam produtos cancerígenos com a matéria orgânica (DEVI \& } \\
\text { DALAI, 2021). }\end{array}$ \\
\hline Possui propriedades oxidantes (Vilas Boas, 2011) & $\begin{array}{l}\text { Formam cloraminas cancerígenas em estômagos de ratos (DEVI \& } \\
\text { DALAI, 2021). }\end{array}$ \\
\hline É solúvel em água (Vilas Boas, 2011) & $\begin{array}{l}\text { Irritação dos olhos e vias respiratórias superiores, causado pela } \\
\text { cloramina (DEVI \& DALAI, 2021). }\end{array}$ \\
\hline $\begin{array}{l}\text { Estudos não demonstram diferenças significativas em grupos de } \\
\text { seres humanos tratados com cloramina (JUN-WEN, 2017). }\end{array}$ & \begin{tabular}{l} 
Volatilizam rapidamente, com o aumento da temperatura \\
\hline
\end{tabular} \\
\hline
\end{tabular}

\section{CLORAMINAS}

Hery, et al.(1998), confirmados pelos estudos de Devi \& Dalai (2021), demonstram que as cloraminas são formadas pela reação do ácido hipocloroso diluído com amônia, especialmente pela interação da amônia, cloro e água. Vários compostos orgânicos que contêm nitrogênio e cloro ligados entre si, como nos grupos $\mathrm{NHCl}$ e $\mathrm{NCl}$ com suas variantes cloramida, cloramina composto cristalino branco $\left(\mathrm{C}_{6} \mathrm{H}_{5} \mathrm{SONClNaHO}\right)$ usado como anti-séptico. Cloramina T: composto cristalino branco, ou levemente amarelo $\left(\mathrm{CH}_{3} \mathrm{C}_{6} \mathrm{H}_{4} \mathrm{SONCINa} 3 \mathrm{HO}\right)$, usado também como anti-séptico.

Segundo Merck (2011), a cloramina T (trihidrato) é corrosiva; nociva por ingestão; provoca queimaduras na pele e lesões oculares graves; quando inalado, ocorrem sintomas de alergia ou de asma ou dificuldades respiratórias; em contato com ácidos libera gases tóxicos. Brasil (2000), determina o máximo de $0,5 \mathrm{mg} . \mathrm{L}^{-1}$ para cloro e $0,15 \mathrm{mg} . \mathrm{L}^{-1}$ para a cloramina para o funcionamento dos serviços de diálise em saúde pública.

Figura 1. Cloramina T.

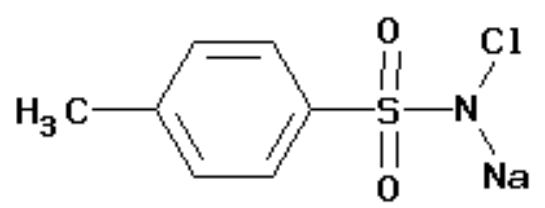

Fonte: Merck (2011) 


\section{CONSIDERAÇÕES FINAIS}

Percebe-se que os sanitizantes clorados são largamente utilizados nas agroindústrias em todo o mundo. Estudos relatam que os sanitizantes clorados produzem uma substância tóxica, chamada cloramina, a qual é cancerígena aos seres humanos. Assim sendo, alternativas ao uso do cloro se fazem necessárias, tais como: uso do ozônio $\left(\mathrm{O}_{3}\right)$, peróxido de hidrogênio $\left(\mathrm{H}_{2} \mathrm{O}_{2}\right)$, ácido peroxiacético ou peracético $\left(\mathrm{CH}_{3} \mathrm{CO}_{3} \mathrm{H}\right)$, raios ultravioletas com comprimento de onda de 250 a $275 \mathrm{~nm}$ possuem atividade germicida. O problema é que estas alternativas são de custo mais elevado e requerem maior aparato tecnológico para serem aplicadas à realidade dos estabelecimentos produtores de alimentos. 


\section{REFERÊNCIAS BIBLIOGRÁFICAS}

BRASIL. Ministério da Saúde. Portaria MS/GM 82. Regulamento técnico para o funcionamento dos serviços de diálise e as normas para cadastramento destes junto ao Sistema Único de Saúde. Diário Oficial da União, Brasília, 8 fev. 2000. Seção 1, p. 13.

DEVI, P.; DALAI, A.K. Implications of breakpoint chlorination on chloramines decay and disinfection by-products formation in brine solution. Desalination. V. 504, n.15, May, 2021 Disponível em: https://www.sciencedirect.com/science/article/abs/pii/S0011916421000321 Acesso em: 01 ago. 2021.

EMMANUEL, E. et al. Toxicological effects of disinfestations using sodium hypochlorite on aquatic organisms and its contribution to AOX formation in hospital wastewater. Environment International, v. 30, p. 891-900, 2014.

GERMANO, P.M.L.; GERMANO, M.I.S. Higiene e vigilância sanitária de alimentos. 6. ed. Barueri:Manole, 2019.

ISONI AUAD, L. et al. Development of a Brazilian Food Truck Risk Assessment Instrument. Int. J. Environ. Res. Public Health, v.15, n. 12, p.2624 2624. 2018. Disponível em: https://doi.org/10.3390/ijerph15122624 Acesso em: 01 ago. 2021.

JUN-WEN, M. et al. Efficacy and Safety Evaluation of a Chlorine Dioxide Solution .Int. J. Environ. Res. Public Health. v. 14, n.3 p.329-340, 2017. Disponível em: https://doi.org/10.3390/ijerph14030329 Acesso em: 01 ago. 2021.

MERCK. Cloramina T (trihidrato). Informe Técnico 102426: Frankfurt, 2011.

SANTOS, F. F.; QUEIROZ, R. C. S.; ALMEIDA NETO, J. A. Evaluation of the application of Cleaner Production techniques in a dairy industry in Southern Bahia. Gestão \& Produção, v. 25, n. 1, p. 117$131,2018$.

VILAS BOAS, E.V. de B. Manual Operacional das Ceasas do Brasil. Belo Horizonte: AD2, 2011. 239 p. (Associação Brasileira das Centrais de Abastecimento).

XI, C. YEN-CON, H. Effects of organic load, sanitizer $\mathrm{pH}$ and initial chlorine concentration of chlorine-based sanitizers on chlorine demand of fresh produce wash Waters. Food Control. v. 77, p.96101, July, 2017. Disponível em: https://www.sciencedirect.com/science/article/abs/pii/S0956713517300361 Acesso em: 01 ago. 2021. 